\title{
Mast cell/IL-4 control of Francisella tularensis replication and host cell death is associated with increased ATP production and phagosomal acidification
}

\author{
AR Rodriguez ${ }^{1}$, J-J Yu ${ }^{1}$, AK Murthy ${ }^{1}$, MN Guentzel ${ }^{1}$, KE Klose ${ }^{1}$, TG Forsthuber ${ }^{1}$, JP Chambers ${ }^{1}$, \\ MT Berton $^{2}$ and BP Arulanandam ${ }^{1}$
}

Mast cells are now recognized as effective modulators of innate immunity. We recently reported that mast cells and secreted interleukin-4 (IL-4) effectively control intramacrophage replication of Francisella tularensis Live Vaccine Strain (LVS), and that mice deficient in mast cells or IL-4 receptor (IL-4R-/-) exhibit greater susceptibility to pulmonary challenge. In this study, we further evaluated the mechanism(s) by which mast cells/IL-4 control intramacrophage bacterial replication and host cell death, and found that IL-4R ${ }^{-/-}$mice exhibited significantly greater induction of active caspase-3 within lung macrophages than wild-type animals following intranasal challenge with either LVS or the human virulent type A strain SCHU S4. Treatment of LVS-infected bone-marrow-derived macrophages with a pancaspase inhibitor (ZVAD) did not alter bacterial replication, but minimized active caspase-3 and other markers (Annexin V and propidium iodide) of cell death, whereas treatment with both rlL-4 and ZVAD resulted in concomitant reduction of both parameters, suggesting that inhibition of bacterial replication by IL-4 was independent of caspase activation. Interestingly, IL-4-treated infected macrophages exhibited significantly increased ATP production and phagolysosomal acidification, as well as enhanced mannose receptor upregulation and increased internalization with acidification, which correlated with observations in mast cell-macrophage co-cultures, with resultant decreases in F. tularensis replication.

\section{INTRODUCTION}

Francisella tularensis is a Gram-negative bacterial pathogen and a potential biological weapon due to ease of dissemination and high mortality following pulmonary infection. ${ }^{1,2}$ F. tularensis subspecies tularensis type A is the most significant and virulent agent of tularemia and may infect humans with as few as 10 organisms resulting in pneumonic disease. ${ }^{3}$ In contrast, F. tularensis subsp. holarctica, also known as type B, is less virulent and causes a milder form of disease that is rarely fatal. ${ }^{1}$ Most studies have used a murine model with the Live Vaccine Strain (LVS) derived from subsp. holarctica to elucidate innate and adaptive immunity following respiratory exposure. F. tularensis LVS primarily infects macrophages and evades lysosomal degradation resulting in high bacterial replication within the cytosol. ${ }^{4-7}$
The respiratory compartment and specifically the lungs are primary sites that encounter respiratory pathogens and have developed dynamic immune defenses for clearance of microorganisms. We recently reported that mast cells, in addition to conventional phagocytic cells, infiltrate the cervical lymph nodes and lungs after intranasal (IN) LVS challenge. ${ }^{8}$ Mast cells have the capacity to produce a broad range of secreted factors and cytokines, including interferon- $\gamma($ IFN- $\gamma)$, tumor necrosis factor- $\alpha$ (TNF- $\alpha$ ), interleukin-4 (IL-4), and interleukin-15 (IL-15), ${ }^{9-12}$ on antigenic stimulation. The high degree of plasticity associated with this cell type allows mast cells to (i) directly phagocytose and kill microorganisms, ${ }^{13-15}$ (ii) influence the activity of other cell types in the vicinity by enhancing cellular recruitment and subsequent activation, ${ }^{16-18}$ and (iii) promote survival by production and induction of cytokines. ${ }^{19}$

${ }^{1}$ Department of Biology, South Texas Center for Emerging Infectious Diseases, University of Texas at San Antonio, San Antonio, Texas, USA. ${ }^{2}$ Department of Microbiology and Immunology, University of Texas Health Science Center, San Antonio, Texas, USA. Correspondence: BP Arulanandam (bernard.arulanandam@utsa.edu) 
Our previous data showed that mast cells significantly inhibit LVS uptake and growth within macrophages through contactdependent events and secreted products, including IL-4. In addition, mice deficient in mast cells or the IL-4 receptor were found to be more susceptible to pulmonary LVS challenge with resultant higher burdens in lungs and spleens than in wild-type animals. ${ }^{8}$ These findings and the pleiotropic nature of IL-4 have led us to further define the mechanisms of mast cell/IL-4 inhibition of $F$. tularensis replication and cell death.

In this study, lung cells from mice deficient in the IL-4 receptor showed increased active caspase- 3 expression in CD11 ${ }^{+}$ macrophages, compared to similarly challenged wild-type animals, following LVS or SCHU S4 challenge. In addition, bonemarrow-derived mast cells effectively reduced intramacrophage replication, as well as the induction of active caspase-3, following in vitro LVS or SCHU S4 challenge. Furthermore, macrophages treated with recombinant IL-4 (rIL-4) during Francisella infection showed decreased expression of the cell death markers active caspase- 3 and poly-ADP-ribosyl protein (PARP), and exhibited reduced propidium iodide uptake. Notably, IL-4 inhibition of bacterial replication was associated with increased ATP production, mannose receptor (MR) recycling, and localization of bacteria within acidified organelles. These results suggest that mast cell and IL-4 reduction of Francisella replication and host cell death are linked through ATP and the resulting enhanced acidification of invading bacterial pathogens.

\section{RESULTS \\ IL-4 signaling regulates active caspase-3 expression in lung macrophages during $F$. tularensis pulmonary infection}

We previously reported that mice deficient in mast cells or IL-4 receptor (R) expression have greater susceptibility to IN LVS challenge. ${ }^{8}$ Given that IL- 4 has been reported to reduce induction of active caspase- 3 and progression to cell death and/or necrosis ${ }^{20}$ we evaluated the lungs of BALB/c IL-4R $\mathrm{R}^{+/+}$ and IL- $4 \mathrm{R}^{-1-}$ mice for expression of active caspase-3 by flow cytometry following IN LVS or SCHU S4 challenge. BALB/c mice were challenged IN with 1,600 CFU of LVS, a dose used in our previous studies, or with 125 CFU of SCHU S4. Lung tissues were collected at day 4 after challenge, and single-cell suspensions were prepared, stained with fluorescent-conjugated CD11b and active caspase- 3 antibodies, and evaluated by flow cytometry. Flow cytometry scatter plots (side scatter vs. active caspase-3, representative SCHU S4 plots shown in Figure 1a) used for analysis of total lung cells, revealed that active caspase3 expression was greater in lung cells obtained from IL- $4 \mathrm{R}^{-/-}$ $\mathrm{KO}$ compared to IL- $4 \mathrm{R}^{+/+}$mice. Given that macrophages are highly permissive to Francisella infection, ${ }^{1,2,4,6,21}$ we specifically analyzed the $\mathrm{CD} 11 \mathrm{~b}^{+}$macrophage population (Figure 1b). As shown in Figure 1c, 29.4\% of macrophages (CD11b ${ }^{\text {hi }}$ gate, black arrow, Figure 1b) were positive for active caspase3 in LVS-challenged IL- $4 \mathrm{R}^{-1-}$ mice compared with $15.5 \%$ in IL- $4 \mathrm{R}^{+/+}$animals at day 4 after challenge $(n=4, P<0.005)$. Cells within the $\mathrm{CD} 11 \mathrm{~b}^{\text {lo }}$ gate (Figure $\mathbf{1 b}$, open arrow), identified as natural killer cells, were negligible for active caspase-3 (data not shown). As expected, there was minimal infiltration of $\mathrm{CD} 11 \mathrm{~b}^{+}$cells or caspase- $3^{+}$cells within the lungs of mockchallenged animals (Figure 1c). Given the degree of active caspase-3 expression following LVS infection, similar analyses were performed on lung cells collected at day 4 from animals challenged IN with the human virulent strain SCHU S4. Active caspase-3 expression was significantly increased in IL-4R ${ }^{-1-}$ mice (19.2\%) compared with IL- $4 \mathrm{R}^{+/+}$mice (10.5\%) after challenge (Figure 1d). Moreover, active caspase- 3 expression also was increased within IL-4R $\mathrm{R}^{-1-}$ CD $11 \mathrm{~b}^{\text {hi }}$ lung macrophages (11.1\%) compared with IL- $4 \mathrm{R}^{+/+}$macrophages (7.1\%). These results suggest that IL-4R-mediated signaling modulates active caspase- 3 expression within the pulmonary compartment following LVS and SCHU S4 challenge.

\section{Mast cells and IL-4 inhibit $\boldsymbol{F}$. tularensis-induced host cell death}

Given that mice deficient in IL-4R signaling exhibited greater caspase- 3 activation following pulmonary $F$. tularensis challenge, we used an established bone-marrow-derived primary macrophage-mast cell co-culture system ${ }^{8}$ to assess directly the role of IL-4 inhibition of host cell death. These analyses revealed that macrophages $\left(\mathrm{CD} 11 \mathrm{~b}^{+}\right.$cells) cultured alone during LVS or SCHU S4 infection (multiplicity of infection $(\mathrm{MOI})=100$ ) exhibited $>40 \%$ active caspase- 3 expression whereas infected macrophages co-cultured in the presence of mast cells exhibited a significant $(P<0.05)$ reduction in caspase-3 activity $(22 \%)$ (Figure 2$)$. A significant $(P<0.05)$ reduction in active caspase- 3 also was evident in macrophages treated with rIL$4\left(25 \mathrm{ng} \mathrm{ml}^{-1}\right)$ and infected with LVS (18\%) and SCHU S4 (27\%). Given the effect of mast cells and IL-4 in reducing F. tularensis-induced caspase- 3 activation, we analyzed additional indicators of host cell death including Annexin V, 22 PARP, and propidium iodide ${ }^{23,24}$ staining by flow cytometry over a time course. Although propidium iodide stains dead and necrotic host cells, Annexin V binds membrane phospholipid phosphatidylserine molecules that are exposed during the early stages of cell death or apoptosis. ${ }^{22}$ Induction of active caspase-3 and PARP is a downstream event following mitochondrial damage and release of cytochrome $c^{23,24}$ These analyses (Figure 3) revealed that induction of active caspase (11\%) and PARP (9\%) as well as Annexin V (12\%) staining was detectable as early as $12 \mathrm{~h}$. At $24 \mathrm{~h}$, LVS-infected macrophages exhibited 62.4, 42.2, $59.3 \%$, and $12.2 \%$ of Annexin $\mathrm{V}^{+}$, active caspase- $3^{+}, \mathrm{PARP}^{+}$cells, and propidium iodide, respectively. Approximately $12.0 \%$ of LVSinfected macrophages were double positive for propidium iodide and Annexin V (data not shown). In comparison, LVS-infected macrophages treated with rIL-4 exhibited a significant $(P<0.05)$ reduction of Annexin V (18.2\%), active caspase-3 (19.0\%), PARP (17.9\%), and propidium iodide (3.2\%) expression at $24 \mathrm{~h}$, compared with untreated infected macrophages. We further examined mast-cell-secreted IL-4 and its influence on cell death by using co-culture systems consisting of wild-type macrophages and STAT6 ${ }^{-1-}$ mast cells that have negligible IL-4 production, but normal TNF- $\alpha$ production. ${ }^{25}$ Macrophages co-cultured with STAT6 ${ }^{-1-}$ mast cells and infected with LVS resulted in a significant loss of mast cell inhibitory effects 


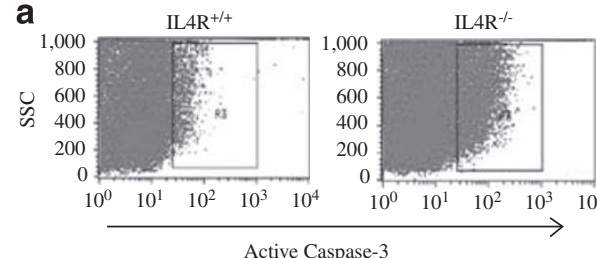

c

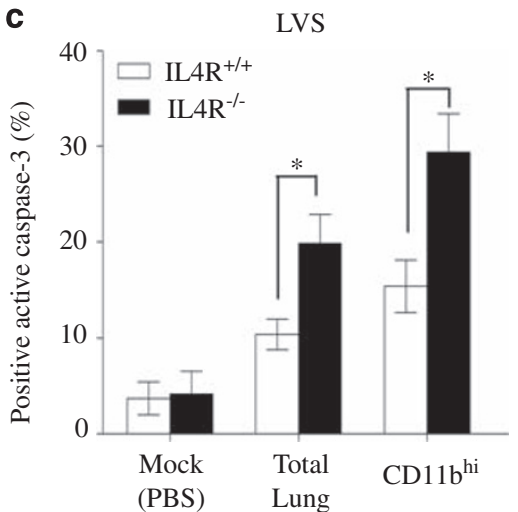

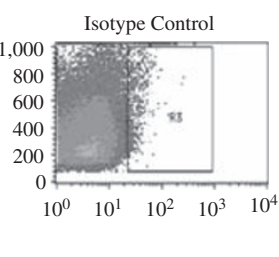

b

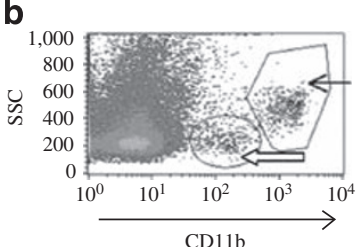

d $\quad$ SCHU S4

cells

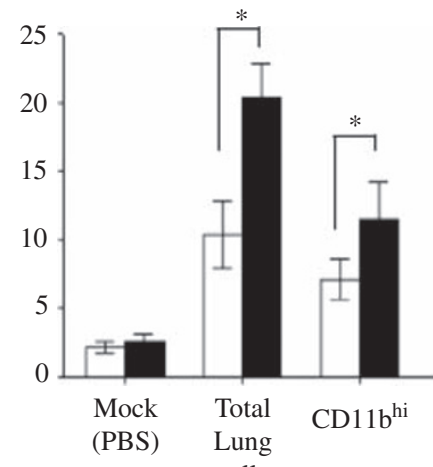

cells

Figure 1 IL-4 signaling regulates active caspase-3 expression in lung macrophages during $F$. tularensis LVS and SCHU S4 pulmonary infection. Lung cells from WT and IL-4R ${ }^{-1}$ mice were analyzed by flow cytometry for active caspase- 3 expression on day 4 after IN LVS challenge (1,600 CFU; $n=4$ per group); or day 4 after SCHU S4 challenge (125 CFU; $n=4$ per group); (a) Total lung cells and total active caspase-3+cells were analyzed; 100,000 events were collected. Representative scatter plots (SCHU S4 IN infection) are shown for total active caspase- $3^{+}$lung cells for WT and IL-4R ${ }^{-/-}$mice, isotype controls, and (b) side scatter vs. CD11b; CD11 bi gate (arrow) used for macrophage analysis (open arrow, CD11 b ${ }^{\text {lo }}$, NK cell population). Expression of active caspase $-3^{+}$total lung cells and CD11 $\mathrm{b}^{+}$active caspase- $3^{+}$lung cells are compared from WT and IL-4R ${ }^{-/-}$mice following LVS (c) or SCHU S4 (d) IN challenge. Unparied $t$-test, ${ }^{*} P<0.05$. Results are representative of three independent experiments. LVS, Live Vaccine Strain; IL-4, interleukin-4.

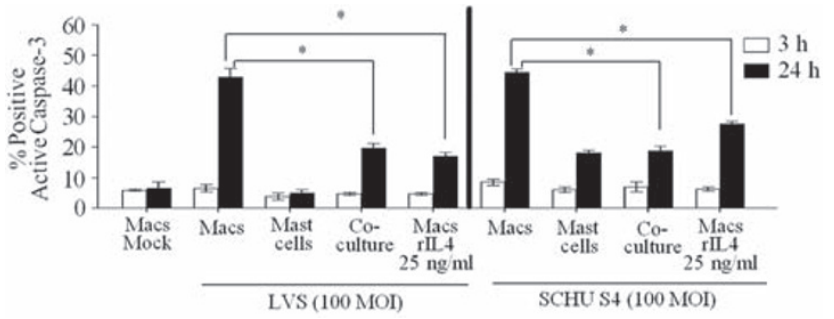

Figure 2 Mast cells inhibit F. tularensis LVS and SCHU S4 induction of active caspase-3. Macrophages, mast cells, co-cultures, or macrophages and $25 \mathrm{ng} \mathrm{ml}^{-1}$ of rlL-4 were infected with LVS $(\mathrm{MOI}=100)$ or SCHU S4 $(\mathrm{MOI}=100)$. Active caspase-3 was evaluated by flow cytometry (mast cells, macrophages, or co-cultures) at 3 and $24 \mathrm{~h}$. Expression of active caspase-3 in LVS or SCHU S4-infected macrophages was compared with infected macrophages in co-culture with mast cells or with addition of rlL-4 $\left(25 \mathrm{ng} \mathrm{ml}^{-1}\right)$. Unpaired $t$-test, ${ }^{\star} P<0.05$. Within co-cultures, cells were gated on $\mathrm{CD} 11 \mathrm{~b}^{+}$for macrophage analysis; 10,000 events were acquired. Results are representative of three independent experiments. LVS, Live Vaccine Strain; rlL-4, recombinant interleukin-4; MOI, multiplicity of infection.

on intramacrophage bacterial replication as well as active caspase-3 expression compared with macrophages cultured with wild-type mast cells (Supplementary Figure S1 online). These results provide additional evidence for the role of mast-cellsecreted products, including IL-4, in modulating host cell death in infected macrophages.

\section{Mast cells promote the maintenance of morphological integrity in macrophages during LVS infection}

To further analyze the pattern of host cell death following F. tularensis infection, we observed changes in cellular morphology by $3 \mathrm{D}$ confocal microscopy in individual cell cultures or co-cultures after $24 \mathrm{~h}$ of infection with Lucifer yellow (green fluorescence)-labeled LVS (MOI = 100) (Figure 4a). These analyses showed that macrophages, but not mast cells, undergo marked morphological changes after LVS infection. Infected macrophages were seen to encompass greater numbers of Lucifer-labeled LVS within the cytoplasm, compared with infected mast cells. In the co-cultures, macrophages showed CD $11 b^{\text {hi }}$, whereas mast cells expressed negligible to minimal CD $11 b^{\text {lo }}$ and also were discernible by morphology. Importantly, LVS-infected macrophages (white arrow) cultured in the presence of mast cells (red arrow) largely retained normal cellular morphology when compared with infected macrophages cultured alone. The structural alteration of cells was further quantitatively evaluated using Imaris software (Figure 4b). Measurements of surface area (LVS $=1,572 \mu \mathrm{m}^{3}$, mock $=425 \mu \mathrm{m}^{3}$ ), volume $\left(\mathrm{LVS}=1,777 \mu \mathrm{m}^{3}\right.$, mock $\left.=2,408 \mu \mathrm{m}^{3}\right)$, and sphericity $(\mathrm{LVS}=0.28$, mock $=0.73$; a value of 1.00 represents a perfect sphere) revealed that macrophages undergo significant quantifiable morphological changes following LVS infection. Macrophages co-cultured with mast cells exhibited more normal morphology (e.g., sphericity: 0.61) compared with macrophages cultured alone (sphericity: 0.28 ). Mast cells showed minimal alterations and comparable quantitative 

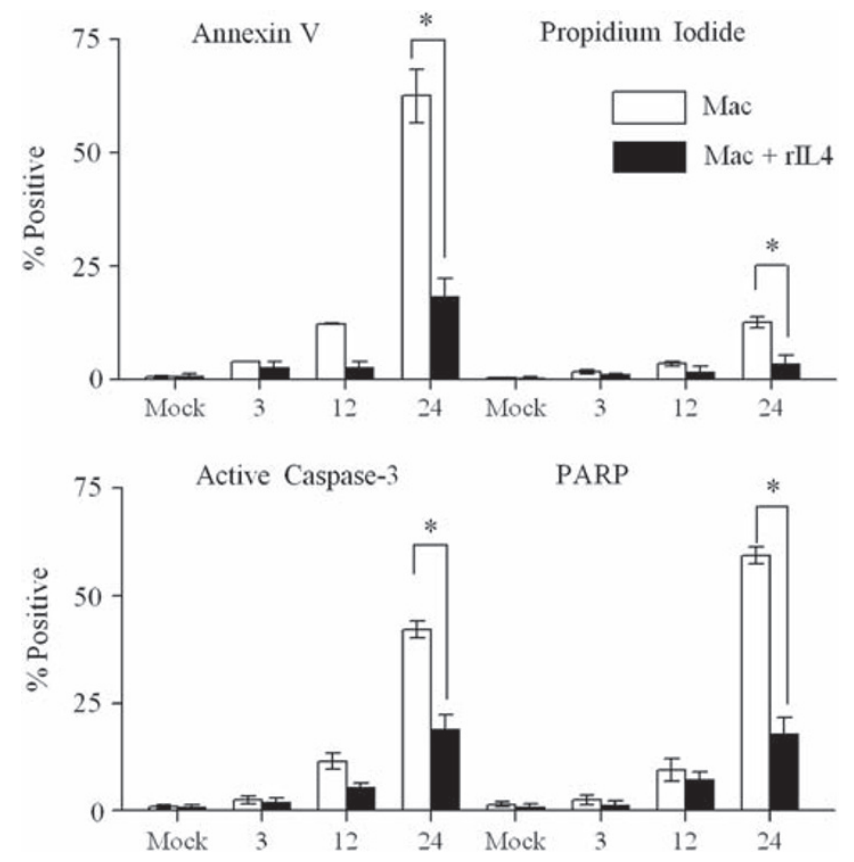

Figure 3 IL-4 inhibits Francisella-induced cell death in macrophages. Macrophages + rIL-4 $\left(25 \mathrm{ng} \mathrm{ml}^{-1}\right)$ were infected with LVS $(\mathrm{MOI}=100)$ and compared to LVS-infected untreated macrophages at 3, 12, and $24 \mathrm{~h}$ for Annexin $\mathrm{V}$ and propidium iodide staining. Uninfected macrophages were used as controls. A separate group of similar treated cells were permeabilized and stained for active caspase-3, and PARP, and analyzed by flow cytometry. Untreated macrophages were compared with rlL-4 (25 $\left.\mathrm{ng} \mathrm{ml}^{-1}\right)$-treated macrophages. Unpaired $t$-test, ${ }^{\star} P<0.05 .10,000$ Events were acquired. Results are representative of three independent experiments. LVS, Live Vaccine Strain; rIL-4, recombinant interleukin-4; MOI, multiplicity of infection; PARP, poly-ADP-ribosyl protein.

morphological measurements after LVS or mock infection. Given that we have previously shown that mast-cell-secreted IL-4 inhibits intramacrophage LVS replication, we next examined if this cytokine is also responsible for maintenance of macrophage morphology in the co-culture system. Uninfected and LVS-infected macrophages were treated with rIL-4 (5 or $25 \mathrm{ng} \mathrm{ml}^{-1}$ ) and also evaluated for surface area, volume, and sphericity. These data revealed that treatment with $\mathrm{rIL}-4$ rescues macrophage morphology (Figure 4c; Supplementary Figure S2 online) in similar manner to mast cells during mast cell-macrophage co-culture. These results further support that mastcell-secreted IL-4 exerts an effect on LVS-infected macrophages that allows these cells to maintain cellular integrity and reduce bacterial replication and cell death.

\section{Inhibition of active caspase-3 does not alter bacterial replication}

To determine if IL-4 inhibition of bacterial replication was dependent on inhibition of active caspase- 3 and host cell death, we used a pancaspase inhibitor, $z V A D,{ }^{26,27}$ during the course of LVS infection. The pancaspase inhibitor was selected given that active caspase- 3 has been suggested to be an important factor during LVS or SCHU S4 infection ${ }^{28}$ and the possibility of involvement of other caspases. In this regard, and in contrast to SCHU S4 and LVS, induction of active caspase-1, which cleaves proIL-1 $\beta$, has been shown to be an important factor during F. novicida infection and ensuing inflammation. ${ }^{29}$ In the mast cell-macrophage co-culture system used for this study, minimal IL-1 $\beta$ was detected in supernatants during LVS infection compared with a much higher quantity produced during F. novicida infection (data not shown), in agreement with previous studies. Thus, macrophages infected with LVS were compared with LVS-infected macrophages that were pretreated with zVAD, zVAD along with rIL-4, or rIL-4 (Figure 5). Interestingly, macrophages treated with zVAD and infected with LVS showed a significant decrease of active caspase- 3 expression (38-5\%); however, bacterial replication was minimally altered. Macrophages treated with zVAD along with rIL4 or with rIL-4 alone during infection showed reductions in both bacterial replication and active caspase-3. These results suggest that although IL-4 limits active caspase- 3 and host cell death, the key mechanism for inhibition of bacterial replication by mast cells/IL-4 may be unrelated to host cell death, but rather to an IL-4-mediated function that is essential for inhibition of both processes upstream of active caspase- 3 .

\section{Interleukin-4 increases cellular ATP, acidification, and mannose receptor expression}

Interleukin-4 has recently been shown to inhibit host cell death by an increase of cellular ATP through increased uptake of glucose. ${ }^{30}$ Furthermore, ATP has been shown to promote phagosome-lysosome fusion and acidification with inhibition of bacterial replication. ${ }^{31,32}$ Therefore, we examined IL-4 modulation of cellular ATP and acidification of phago-lysosomes in conjunction with MR expression during Francisella infection. The MR is important for Francisella recognition and is upregulated by IL- $4 .{ }^{33}$ Macrophages were treated with rIL-4 ( 5 or $25 \mathrm{ng} \mathrm{ml}^{-1}$ ) for $2 \mathrm{~h}$ before infection, cell lysates (normalized by Bradford assay) were analyzed for ATP after $1 \mathrm{~h}$ of infection with LVS, and acidification and MR expression were examined by confocal microscopy and flow cytometry. Macrophages treated with $5 \mathrm{ng} \mathrm{ml}^{-1}$ of rIL-4 exhibited an increase of cellular ATP $(15-18 \mathrm{~mm})$ and a significant $(P<0.001)$ increase $(25 \mathrm{~mm})$ with $25 \mathrm{ng} \mathrm{ml}^{-1}$ of rIL-4 compared with untreated macrophages during LVS infection (Figure 6a). In addition, ATP production was significantly increased in LVS-infected macrophages treated with $25 \mathrm{ng} \mathrm{ml}^{-1}$ compared with uninfected macrophages treated with the same concentration, suggesting a possible synergistic induction of ATP in LVS-infected macrophages with addition of rIL-4. Because ATP enhances phagosome acidification, an acidification probe was added during the last $30 \mathrm{~min}$ of infection for evaluation of phagosome acidity. The acidification probe is a fluorophore containing a weakly basic amine that selectively accumulates in acidic organelles and can be used in labeling live cells. ${ }^{34}$ Cells were surface stained with anti-CD206 (MR) and anti-CD11b at room temperature, and 4', 6-diamidino-2-phenyl indole (DAPI) was added after final wash of antibodies. Surprisingly, confocal microscopy imaging, which allows 3D analysis, 
a

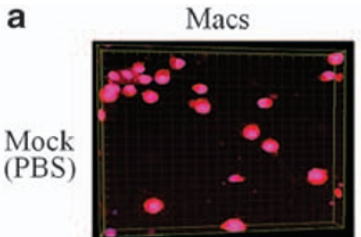

LVS

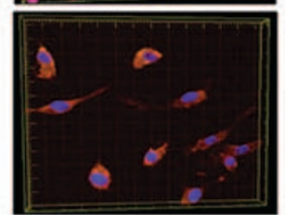

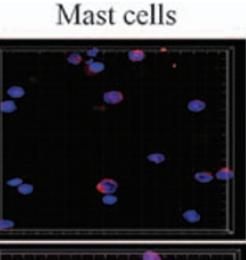

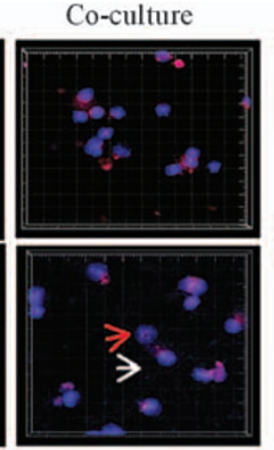

b
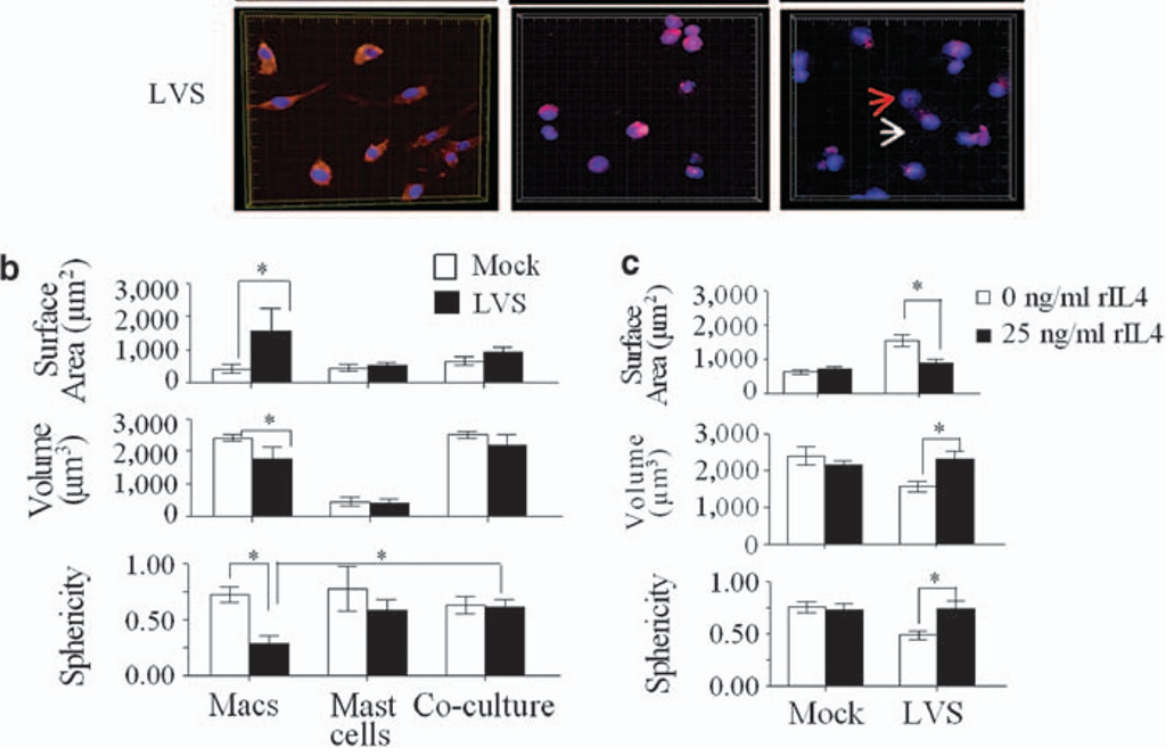

Figure 4 Macrophages show reduced morphological alterations in co-culture with mast cells during F. tularensis LVS infection. Mast cells, macrophages, or co-cultures were infected $(\mathrm{MOI}=100)$ with Lucifer yellow-labeled LVS. (a) Cells were analyzed by confocal microscopy after $24 \mathrm{~h}$ in culture. Macrophages were stained with anti-CD11b PE (red), whereas mast cells were stained with anti-FcERI PE (red) and nuclear stain (blue). Macrophages (white arrow), mast cells (red arrow). Magnification, $\times 400$. (b) Cells from culture were quantitatively analyzed by Imaris software for area, volume, and sphericity (1.00 represents a perfect sphere) after LVS infection. ( $\left.{ }^{*} P<0.05\right)$ LVS-infected macrophages compared with mockinfected macrophages. Comparison of sphericity of LVS-infected macrophages compared to mast cell macrophage co-cultures (c) Uninfected or LVS-infected macrophages were treated with rlL-4 $\left(25 \mathrm{ng} \mathrm{ml}^{-1}\right)$ or untreated and cellular morphology was compared for surface area, volume, and sphericity. Unpaired $t$-test, ${ }^{*} P<0.05$. Results are representative of three independent experiments. LVS, Live Vaccine Strain; rlL-4, recombinant interleukin-4; MOI, multiplicity of infection; PE, phycoerythrin.

showed that while the cells were only surface stained with anti-CD206 and anti-CD11b (cell permeabilizing agents were not used), the MR fluorescent-conjugated antibody was taken into the macrophages and colocalized (white arrows) with the acidification probe that labels acidic organelles (Figure $6 \mathbf{b}$ ). This colocalization of MR with acidification regions was notably higher in rIL-4-treated compared to untreated macrophages. To further quantify MR expression, we compared untreated macrophages with rIL-4-treated macrophages, and analyzed by flow cytometry (Figure 6c). Analyses revealed that rIL-4-treated macrophages showed a significant increase of MR expression compared with untreated macrophages during LVS infection. Furthermore, infected macrophages in co-culture with mast cells significantly increased MR expression from approximately $40 \%$ to more than $80 \%$ (Figure 6c). To further examine the significance of MR upregulation and acidification, we generated MR-deficient macrophages from C57BL/6 $\mathrm{MR}^{-1-}$ mice. ${ }^{35}$ Wild-type and $\mathrm{MR}^{-1-}$ macrophages were treated with rIL-4 and infected with LVS, and compared with untreated LVS-infected macrophages for bacterial replication, MR expression, ATP (Figure 7), and acidification (Supplementary Figure S3 online). Given that additional mechanisms for bacteria uptake have been previously suggested, ${ }^{36}$ it was not surprising that $\mathrm{MR}^{-/-}$macrophages also phagocytosed LVS. Addition of rIL-4 increased ATP in $\mathrm{MR}^{-1-}$ macrophages as expected, however bacterial reduction was not significant, and a high percentage of bacteria did not colocalize with acidified regions (Supplementary Figure S3 online). In separate experiments, addition of rIL-4 to IL-4receptor-deficient macrophages did not alter bacterial replication, MR expression, or ATP production (Figure 8). Together, these data show that mast cells and IL-4 increase MR expression, and importantly, suggest that mast-cell-secreted IL-4 promotes uptake and acidification of MR in organelles during F. tularensis infection.

\section{Interleukin-4 promotes colocalization of Francisella within acidified organelles}

Given our findings that mast cells and IL-4 enhance MR expression and acidification of recycling receptors, we next determined if intramacrophage Francisella organisms were contained within acidified organelles or regions using Lucifer-labeled LVS. We analyzed untreated and rIL4-treated macrophages with addition of an acidification 

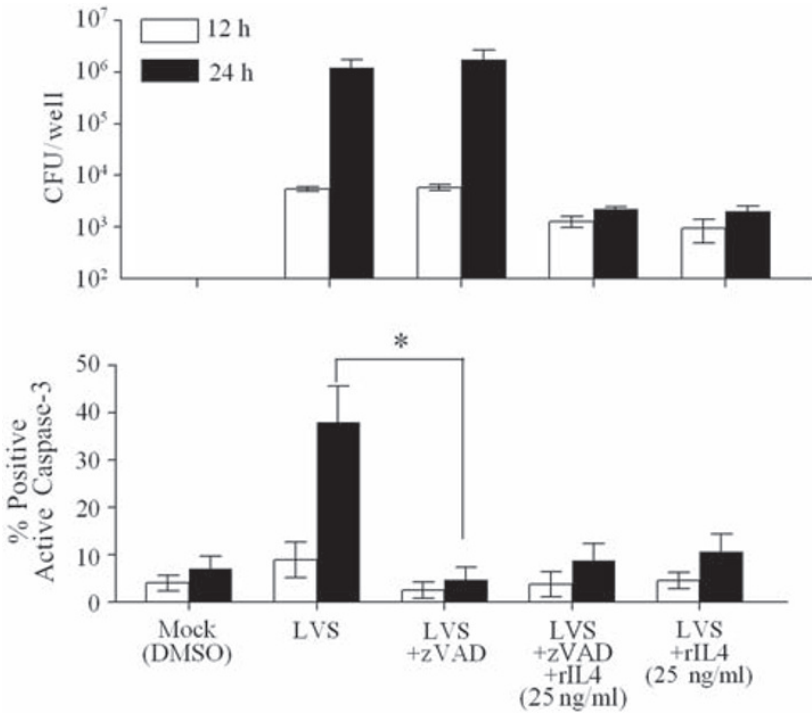

Figure 5 Inhibition of active caspase-3 does not alter bacterial replication. Macrophages, macrophages + ZVAD $(20 \mu \mathrm{m})$, macrophages $+\mathrm{ZVAD}(20 \mu \mathrm{m})$ and rlL-4 $\left(25 \mathrm{ng} \mathrm{ml}^{-1}\right)$, or macrophages $+\mathrm{rlL}-4\left(25 \mathrm{ng} \mathrm{ml}^{-1}\right)$ were infected $(\mathrm{MOI}=100)$ with LVS and compared for bacterial replication and active caspase-3 induction at 12 and $24 \mathrm{~h}$. Unpaired $t$-test, ${ }^{\star} P<0.05$. Results are representative of three independent experiments. LVS, Live Vaccine Strain; rlL-4, recombinant interleukin-4; MOI, multiplicity of infection.

probe during the last $30 \mathrm{~min}$ of LVS infection in vitro and analyzed cells by confocal microscopy (Figure 9). At $1 \mathrm{~h}$ after challenge, untreated macrophages contained numerous Lucifer-labeled LVS (green) visible with minimal colocalization (yellow) with acidification regions (red). However, in rIL-4-treated macrophages, the lower number of Luciferlabeled LVS (green) colocalized with the numerous sphereshaped regions encompassed by the acidification probe (Figure 9) with Lucifer-labeled LVS colocalizing as yellow. Interestingly, 3D enlargement and comparison of the acidified regions revealed that addition of rIL-4 results in notable encompassing of bacteria within the red acidified regions, in contrast to untreated LVS-infected macrophages (Figure 9a, 3D enlargement). This may suggest that the bacteria in the untreated macrophages escape the phagosome, rather than efficiently killed as in the rIL-4-treated macrophages. Furthermore, statistical analysis of Francisella within the acidification regions using Imaris software (Bitplane, St Paul, MN) showed that $>80 \%$ of the Lucifer-labeled bacteria in the rIL-4-treated macrophages localized within the acidified regions compared with $<10 \%$ (Figure 9 b) in the untreated macrophages. We further examined IL-4 influence on phagosome acidification using IL-4-receptor-deficient macrophages in co-culture with mast cells and compared resulting acidification to wild-type mast cell macrophage co-cultures. These experiments revealed a notable increase of acidification regions and decreased Lucifer-labeled LVS in wild-type co-cultures, but reduced acidification in IL$4 \mathrm{R}^{-1-}$ macrophages (Supplementary Figure S4 online). However, after $24 \mathrm{~h}$ LVS infection $(\mathrm{MOI}=100), \mathrm{IL}-4 \mathrm{R}^{-/-}$ a

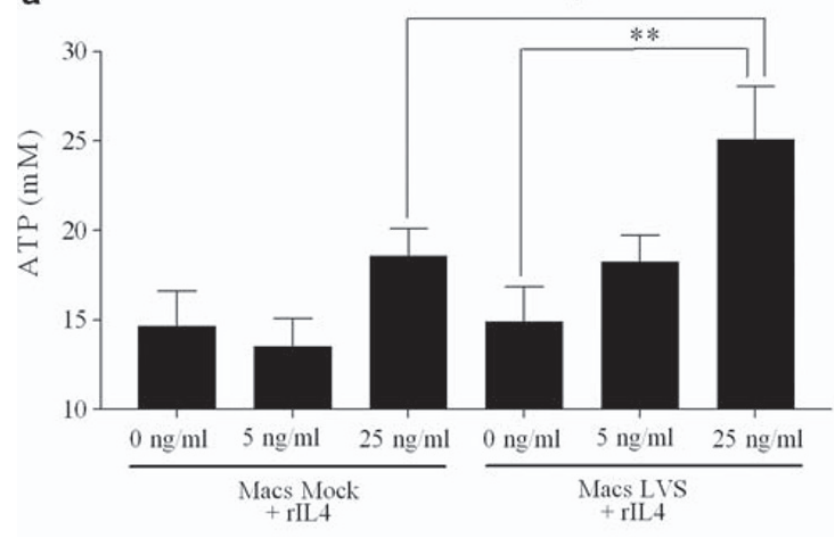

b
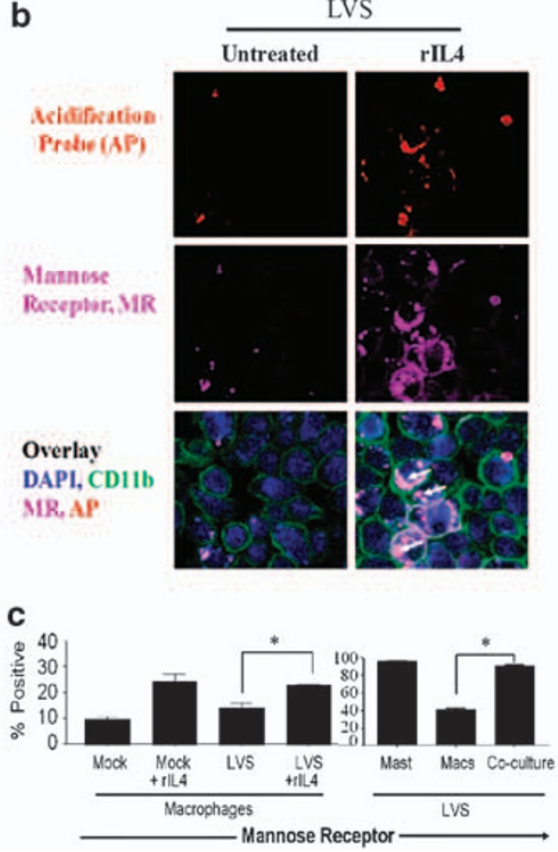

Figure 6 IL-4 promotes ATP production and mannose receptor expression with recycling. (a) Uninfected macrophages and macrophages + rlL-4 ( 5 or $25 \mathrm{ng} \mathrm{ml}^{-1}$ ) were compared to LVS-infected $(\mathrm{MOI}=100)$ macrophages and LVS-infected macrophages + rlL-4 (5 or $25 \mathrm{ng} \mathrm{ml}^{-1}$ ) for induction of ATP production by bioluminescence assay. Unpaired $t$-test, ${ }^{*} P<0.05,{ }^{*} P<0.001$. (b) LVS-infected $(\mathrm{MOI}=100)$ macrophages were compared with LVS-infected macrophages + rlL$4\left(25 \mathrm{ng} \mathrm{ml}^{-1}\right)$ and analyzed by confocal microscopy (original magnification, $\times 400$ ). Macrophages were treated with the acidification probe during incubation and surfaced stained with anti-CD206 (MR, purple), anti-CD11b (green), and DAPI (nuclear stain, blue). Representative images are compared for untreated and rlL-4-treated macrophages: acidification probe (red), and MR (purple) alone and colocalization of internalized MR (white arrow) and organelle acidification probe (pink). (c) Macrophages $( \pm$ rlL-4 treatment), mast cells or co-cultures were infected $(\mathrm{MOI}=100)$ with LVS and analyzed for MR expression; macrophages in co-culture were analyzed within the CD11b gate; 10,000 events were acquired. Unpaired $t$-test, ${ }^{\star} P<0.05$. Results are representative of three independent experiments. LVS, Live Vaccine Strain; rlL-4, recombinant interleukin-4; MOI, multiplicity of infection; DAPI, 4', 6-diamidino-2-phenyl indole; MR, mannose receptor.

macrophages in co-culture with mast cells exhibited high cell lysis, which may be directly related to lack of IL-4 uptake and resulting cell death. Thus, by use of the acidification 

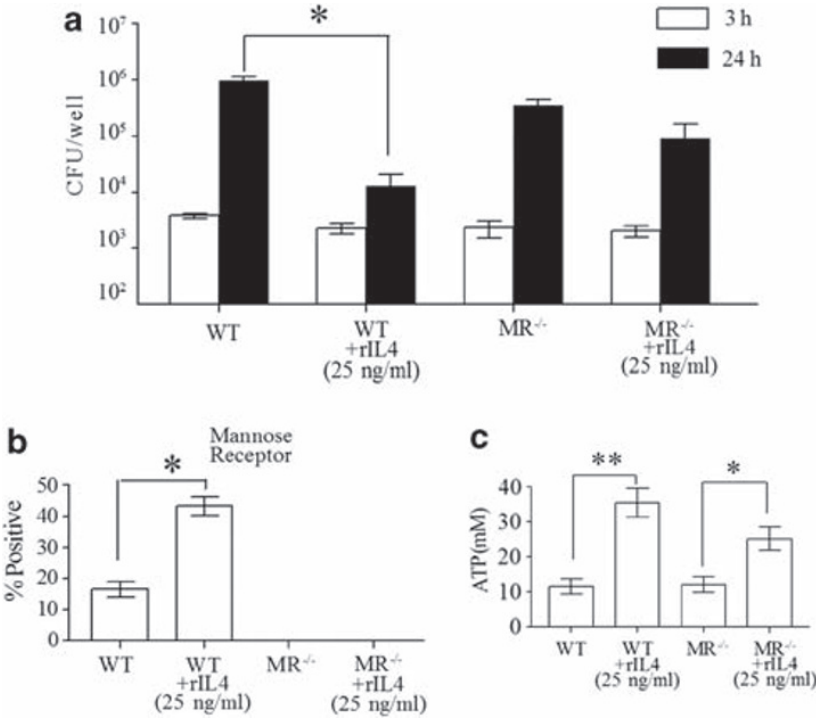

Figure 7 Mannose-receptor-deficient macrophages exhibit reduced bacterial killing compared with WT macrophages. WT and $\mathrm{MR}^{-1-}$ macrophages were treated $\mathrm{rlL}-4\left(25 \mathrm{ng} \mathrm{ml}^{-1}\right)$, infected with LVS $(\mathrm{MOI}=100)$, and compared with corresponding untreated LVS-infected $(\mathrm{MOI}=100)$ macrophages. Cells were analyzed for bacterial replication (a), MR expression (b), and ATP production (c) as previously described. Unpaired $t$-test, ${ }^{*} P<0.003$. LVS, Live Vaccine Strain; rlL-4, recombinant interleukin-4; MOI, multiplicity of infection; MR, mannose receptor; WT, wild type.
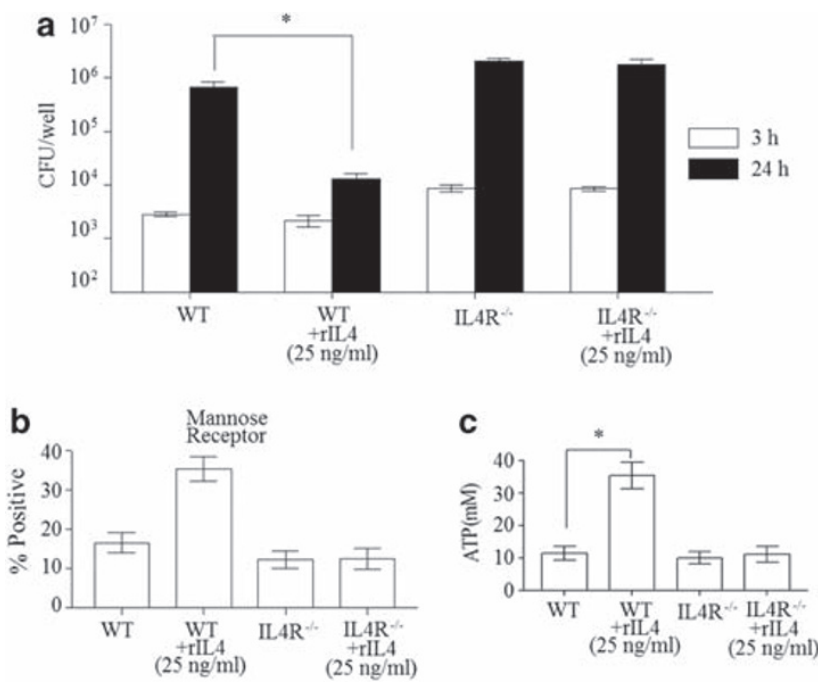

Figure 8 IL-4-receptor-deficient macrophages do not exhibit increased ATP production or mannose receptor expression with rlL-4 treatment. WT and IL-4R-1- macrophages were treated with rlL-4 (25 $\left.\mathrm{ng} \mathrm{ml}^{-1}\right)$, infected with LVS $(\mathrm{MOI}=100)$, and compared with corresponding untreated LVSinfected $(\mathrm{MOI}=100)$ macrophages. Cells were analyzed for bacterial replication (a), MR expression (b), and ATP production (c) as previously described. Unpaired $t$-test, ${ }^{\star} P<0.003$. LVS, Live Vaccine Strain; rIL-4, recombinant interleukin-4; $\mathrm{MOI}$, multiplicity of infection; MR, mannose receptor; WT, wild type.

probe, which is highly selective for acidic organelles, we showed that mast-cell-secreted IL-4 improves acidification of Francisella within macrophages.

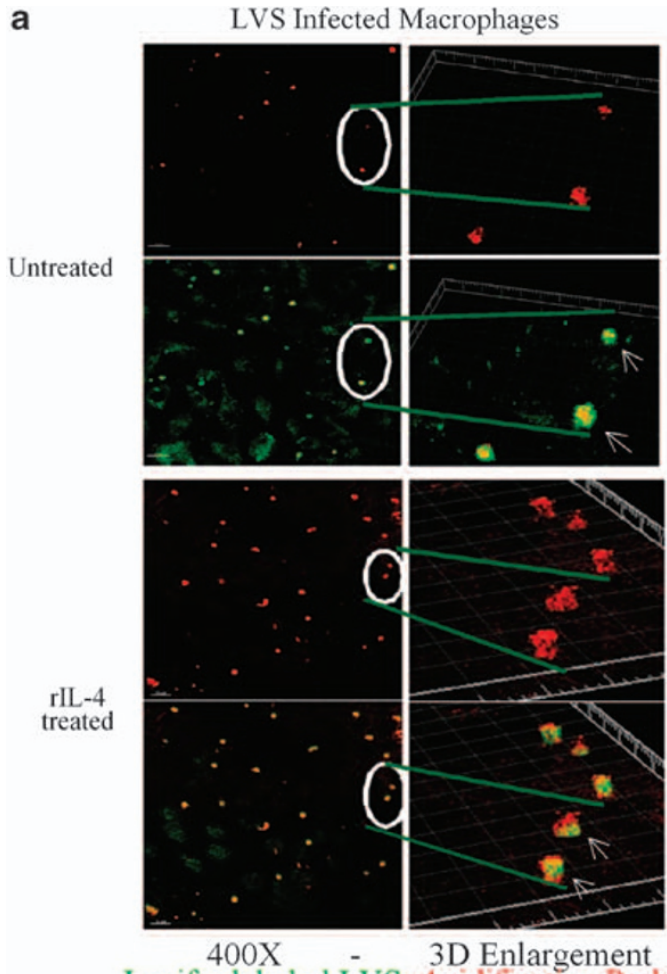

Lucifer labeled LVS, Acidification Probe

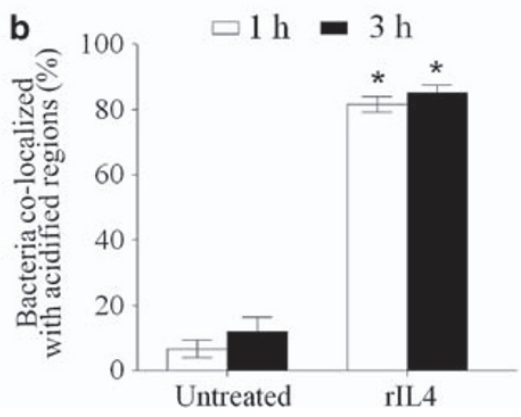

Figure 9 Interleukin-4 promotes colocalization of Francisella within acidified organelles. Lucifer-labeled LVS (green)-infected (MOI = 100) macrophages were compared with Lucifer-labeled LVS (green)-infected macrophages + rlL-4 (25 $\left.\mathrm{ng} \mathrm{ml}^{-1}\right)$ and analyzed by confocal microscopy (original magnification, $\times 400$ ) at $1 \mathrm{~h}$ after challenge. Macrophages were treated with the organelle acidification probe (red) during incubation. (a) Representative images are compared for untreated and rlL-4-treated macrophages: acidification probe (red) alone, and colocalization of Lucifer-labeled LVS (green) with acidification probe (yellow). 3D enlargement of the acidified organelles: Lucifer-labeled LVS, and colocalization shown (white arrows). (b) Lucifer-labeled LVS-infected $(\mathrm{MOI}=100)$ macrophages were compared with Lucifer-labeled LVSinfected macrophages + rlL-4 $\left(25 \mathrm{ng} \mathrm{ml}^{-1}\right)$ and analyzed using Imaris software at 1 and $3 \mathrm{~h}$ after challenge. 3D spot localization analysis of Lucifer yellow $(488 \mathrm{~nm}$ channel, greater than $0.8 \mu \mathrm{m})$ and acidification probe $(594 \mathrm{~nm}$ channel, greater than $2.0 \mu \mathrm{m})$ were compared to colocalization (Lucifer yellow with red) and calculated as a percent of the total for the two groups. At least 100 cells were analyzed from each group, ${ }^{*} P<0.002$. LVS, Live Vaccine Strain; rlL-4, recombinant interleukin-4; MOI, multiplicity of infection; MR, mannose receptor.

\section{DISCUSSION}

Mast cells are efficient innate immune responders located at mucosal surfaces and within tissues. ${ }^{37,38}$ We previously reported 
that mast cells migrate to the lungs during F. tularensis LVS pulmonary infection and that mast-cell-secreted IL-4 significantly reduces intramacrophage replication. ${ }^{8}$ In this study, we further analyzed mast cell/IL-4-mediated inhibition of bacterial replication and host cell death using mice deficient in IL-4 signaling. These mice (IL-4R $\mathrm{R}^{-/-}$) exhibited significantly higher levels of active caspase-3, a known cysteine protease associated with cell death, ${ }^{39}$ compared with wild-type mice, following LVS or human virulent SCHU S4 pulmonary challenge. However, there was higher macrophage recruitment to the lungs and increased cell death within this population following LVS infection compared with SCHU S4. This increase in active caspase-3 expression within lung macrophages of LVS- or SCHU S4-infected IL-4R $\mathrm{R}^{-1-}$ mice suggests a physiological contribution of IL-4 in modulating host cell death following pulmonary infection. In this regard, Wickstrum et al. ${ }^{28}$ have recently reported that mice infected by aerosolization of SCHU S4 show active caspase-3 and cell death, but minimal cleaved caspase- 1 associated with the inflammasome, within the lungs.

Notably, our study shows a plausible mechanism by which IL-4-mediated inhibition of F. tularensis replication is associated with increased ATP production and improved acidification of organelles containing bacteria. Specifically, IL-4 increased ATP production, and MR expression and uptake with increased colocalization of MR within acidified regions in macrophages, as well as localization of Lucifer-labeled F. tularensis to the acidified organelles. Interestingly, addition of rIL-4 resulted in bacteria well encompassed by acidified regions in contrast to untreated macrophages. Furthermore, when IL- $4 \mathrm{R}^{-1-}$ macrophages were co-cultured with mast cells, there was reduced acidification and increased Lucifer-labeled bacteria compared with wild-type macrophages in co-culture with mast cells (Supplementary Figure S4 online). Also, at $24 \mathrm{~h}, \mathrm{IL}-4 \mathrm{R}^{-/-}$macrophages in coculture with mast cells showed greater cell lysis than wild-type macrophages, which may be directly related to lack of IL-4 uptake and resulting cell death. These results provide a foundation by which mast cells and IL-4 production mediate reduction of bacterial replication and host cell death associated with the modulation of ATP expression.

To analyze parameters associated with cell death following bacterial infection, we evaluated the effect of mast cells on LVS and SCHU S4 intramacrophage replication and induction of apoptosis. Under similar co-culture conditions, mast cells were shown to inhibit the intramacrophage replication of SCHU S4 and LVS, and to diminish active caspase-3 induction. In addition, infected macrophages treated with rIL-4 showed decreased Annexin V and propidium iodide staining. To determine if the inhibition of bacterial burden was dependent on the reduction of host cell death, we used a pancaspase inhibitor, zVAD. Although active caspase- 3 was significantly diminished in the presence of the inhibitor, bacterial replication was not altered, suggesting that the effect of IL-4 was upstream and independent of active caspase- 3 inhibition. IL-4 upregulation of ATP by enhanced glucose uptake has been shown to inhibit cell death. ${ }^{30}$ In addition, IL-4 upregulates Bcl-xL, which functions in maintenance of mitochondrial integrity 30,40 and prevention of cell death upstream of cytochrome $c$ release, thereby reducing the progression to necrosis. ${ }^{20}$ Interestingly, ATP also has been shown to promote phagosome-lysosome fusion and intracellular killing of bacterial pathogens. ${ }^{31,32}$ Our recent findings ${ }^{8}$ and current reports ${ }^{30-32}$ suggest that the association between IL-4 inhibition of Francisella bacterial replication and host cell death may result from increased ATP production. Enhancement of ATP not only supports cell survival, but also promotes acidification and killing of invading pathogens.

In addition, to determine if the inhibitory effects observed with mast cells are mast cells specific, primary hepatocytes were co-cultured with macrophages, and then infected with LVS as conducted in previous experiments of co-culture with mast cells. Bacterial replication and macrophage active caspase- 3 expression were not altered (data not shown), supporting the findings that inhibition is dependent on mast-cell-secreted IL-4. Although mast cell spent supernatant or rIL-4 treatment reduced LVS intramacrophage replication, the levels of nitric oxide were not increased (Supplementary Figure S5 online). Therefore, nitric oxide is ruled out as a possible factor influencing bacterial reduction. In addition, STAT6 ${ }^{-1-}$-deficient mast cells that do not produce detectable levels of IL-4, did not reduce bacterial replication or active caspase- 3 expression in macrophages during co-culture. Considering that TNF- $\alpha$ has been shown to amplify IL-4 receptor signaling through inactivation of protein tyrosine phosphatase $1 \mathrm{~B},{ }^{41}$ we also examined the effects of neutralizing antibody against TNF- $\alpha$. This neutralizing antibody reduced the levels of IL-4 (data not shown) in the system and the inhibitory effects of mast cells in co-culture. The highest level of abrogation of mast cell effects resulted with addition of antiIL-4 and anti-TNF- $\alpha$ to the co-culture system during LVS infection (Supplementary Figure S6 online). In view of the fact that Francisella-infected macrophages produce TNF- $\alpha$, this cytokine alone is not responsible for the decrease of bacterial replication or macrophage cell death observed with mast cells/IL-4. The IL-4/TNF- $\alpha$ feedback mechanism during Francisella infection is currently under further investigation.

Interleukin- 4 has been shown to enhance MR expression and increase recycling of these receptors into the lysosomes. ${ }^{33,42}$ In addition, upregulation of MR has been reported to be essential to the control of pulmonary pathogens such as Pseudomonas ${ }^{43}$ and Mycobacterium. ${ }^{44}$ To this end, Schulert and Allen ${ }^{33}$ showed that IL-4 treatment promotes phagocytosis of LVS and upregulation of MR expression within infected macrophages. However, the degree of expression of IL-4 and the origin (e.g., peritoneal or bone marrow derived) of macrophages may lead to phenotypic differences in cellular activity. MR expression induced by extended $(48 \mathrm{~h}) \mathrm{rIL}-4$ pretreatment compared with the short-term $(2 \mathrm{~h})$ pretreatment used in this study was associated with decreased phagocytosis and inefficient bacterial killing. ${ }^{45}$ The inefficient bacterial killing during extended rIL-4 treatment may promote excessive stimulation and reduced recycling of the MR. This is supported by a recent finding that sustained receptor stimulation results in sequestration of recycling endosomes. ${ }^{46}$ Given the plasticity of mononuclear cells and 
the stimuli of the microenvironment (i.e., peritoneal, lung, systemic, or tissue), there may be several facets to the response of macrophages to cytokines such as IL-4 in vivo. Collectively, our recent findings provide new insights to the contribution of mast cells and secreted IL- 4 in mediating antibacterial innate immunity.

\section{METHODS}

Mice. Specific pathogen-free 4- to 8-week-old mice were used for all procedures. $\mathrm{C} 57 \mathrm{BL} / 6$ and $\mathrm{BALB} / \mathrm{c}$ mice were purchased from the National Cancer Institute. BALB/c IL-4R $\mathrm{R}^{-1-}$ mice $^{47}$ were purchased from Taconic Farms. C57BL/6 $\mathrm{MR}^{-1-}$ mice were a generous gift from Dr Gary Cole. All experimental procedures and animal care were performed in accordance with the Institutional Animal Care and Use Committee guidelines.

Bacteria. Francisella tularensis LVS (obtained from Dr R Lyons at University of New Mexico) and F. tularensis SCHU S4 (obtained from the Centers for Disease Control) were grown in tryptic soy broth supplemented with L-cysteine. ${ }^{8}$ Experiments using SCHU S4 were conducted in a licensed ABSL-3 facility.

Generation of primary cells and in vitro infection. Macrophages and mast cells were derived from mouse bone marrow and infected in vitro as described previously. ${ }^{8}$ Briefly, cells were counted, plated, and incubated for a 4 -h rest period without cytokines before infection. Cells were infected for $2 \mathrm{~h}$, treated with gentamicin for $1 \mathrm{~h}$, washed, incubated at $37^{\circ} \mathrm{C}$, and analyzed at various time points. At 3,12 , or $24 \mathrm{~h}$ after infection with LVS $(\mathrm{MOI}=100)$ or F. tularensis SCHU S4 $(\mathrm{MOI}=100)$, bacteria were enumerated using cellular lysates. In separate experiments, murine recombinant IL-4 (rIL-4, 5 or $25 \mathrm{ng} \mathrm{ml}^{-1}$; eBioscience, San Diego, CA) was added to cultures $2 \mathrm{~h}$ before infection and rIL-4 was replaced after each wash step. Cells were used for determination of bacterial replication, or active caspase- 3 expression. For caspase inhibition experiments, z-VAD FMK (Fluromethylketone; BD Pharmingen, San Jose, CA), a pancaspase inhibitor, was dissolved in DMSO, and added to cultures $30 \mathrm{~min}$ before addition of rIL-4. Similar concentrations of DMSO were used as controls.

In vivo challenge and flow cytometry. BALB/c (6- to 8-week-old, IL-4R $\mathrm{R}^{+/+}$and IL-4R $\mathrm{R}^{-/-}$) mice were challenged IN with $1,600 \mathrm{CFU}$ of LVS (a dose used in our previous studies) or phosphate-buffered saline (PBS, mock challenge). At day 4 after challenge, mice were killed. In addition, $\mathrm{BALB} / \mathrm{c}\left(\mathrm{IL}-4 \mathrm{R}^{+/+}\right.$and IL-4R ${ }^{-/-}$) mice were challenged IN with $125 \mathrm{CFU}$ of SCHU S4 or PBS and were killed in a similar manner at day 4 after challenge. The lungs were perfused with $1 \times \mathrm{PBS}$, then excised and placed in a sterile dish. Lungs were rinsed with cold 10\% RPMI and transferred to fresh media. The lung tissue was minced, and cells were filtered through a $70 \mu \mathrm{m}$ strainer. The cells were then treated with collagenase $\left(0.7 \mathrm{mg} \mathrm{ml}^{-1}\right)$ and DNAse and incubated at $37^{\circ} \mathrm{C}$ for $15 \mathrm{~min}$. Next, the lung cells were washed in cold 10\% RPMI, and RBC lysis buffer was added to the cells. The cells were incubated for $5 \mathrm{~min}$ at $37^{\circ} \mathrm{C}$, washed, and aliquoted into polystyrene tubes at $1 \times 10^{6}$ for staining with fluorescent-conjugated antibodies. Next, the cells were washed with $2 \%$ fetal bovine serum in $1 \times$ PBS with $0.09 \%$ sodium azide (PBS wash), then blocked with $10 \%$ rat sera $1 \times$ anti $\mathrm{PBS}$ at $4^{\circ} \mathrm{C}$ for $30 \mathrm{~min}$. Samples were washed and surfaced stained with CD11b allophycocyanin (APC) or isotype control (IgG2a $\kappa$ $\mathrm{APC}$ ), incubated at $4^{\circ} \mathrm{C}$ for $30 \mathrm{~min}$, and washed. The samples were then fixed in Cytofix/Cytoperm for $20 \mathrm{~min}$, washed with PBS wash, and treated with $1 \times$ PermWash for $10 \mathrm{~min}$ and wash was removed. Active caspase- 3 phycoerythrin (PE; clone C92-605; BD Biosciences), or isotype control (IgG1 PE) was diluted in $100 \mu \mathrm{l} 1 \times$ PermWash, and added to appropriate samples. Samples were incubated for $60 \mathrm{~min}$ with intermittent vortexing, washed in $1 \times$ PermWash, and resuspended in $2 \%(\mathrm{w} / \mathrm{v})$ paraformaldehyde for flow cytometer (FACSCalibur; BD Biosciences) analyses. Analyses were performed using CellQuest Pro software (BD Biosciences).

For in vitro analysis of macrophages, mast cells, and co-cultures, we collected cells at 3,12 , or $24 \mathrm{~h}$ and washed in PBS wash. Samples were subsequently blocked with anti-mouse CD16/CD32 (BD Biosciences), or 10\% rat sera at $4^{\circ} \mathrm{C}$, followed by addition of fluorescent-conjugated antibodies for surface and/or intracellular staining as noted above. Fluorescent antibodies included FceRI (PE), c-Kit fluorescein isothiocyanate (FITC) (clone 2B8; eBioscience), CD11b (FITC or APC, allophycocyanin), CD206 (clone MR5D3; BioLegend, San Diego, CA) active caspase-3 PE (Clone C92-605; BD Biosciences), or cleaved PARP PE (clone F21-852; BD Biosciences)

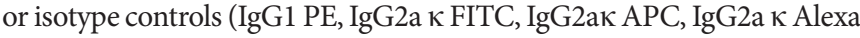
488). Gating for analyses included side scatter vs. c-Kit for primary mast cells, or CD11b for macrophages. In separate experiments, samples were washed with $1 \times$ binding buffer and stained for $15 \mathrm{~min}$ with cell death markers Annexin V-FITC and propidium iodide for $15 \mathrm{~min}$; unstained samples were used as controls. The samples were then washed with $1 \times$ binding buffer (BD Biosciences), resuspended in $400 \mu \mathrm{l} 1 \times$ binding buffer, and acquired (FACSCalibur) within $30 \mathrm{~min}$. Analyses were performed using CellQuest Pro software (BD Biosciences).

Microscopy. LVS bacteria were labeled with Lucifer yellow (Sigma, St Louis, MO $)^{48}$ at $37^{\circ} \mathrm{C}$ for $2 \mathrm{~h}$, washed, and placed on ice. Lucifer-labeled bacteria were used for in vitro infection as described in the previous section, however mast cells and macrophages were cultured on coverslips in 24-well plates. For analysis of acidification, ${ }^{34}$ a specific acidification probe (LysoTracker Red DND-99; Invitrogen, Eugene, OR) was added for $30 \mathrm{~min}$ to $1 \mathrm{~h}$ in culture at $37^{\circ} \mathrm{C}$, followed by several washings. CD206 Alexa 488 was added to cells at room temperature for $30 \mathrm{~min}$ and washed. Additional staining with fluorescent-conjugated antibodies to Fc\&RI (PE) or $\mathrm{CD} 11 \mathrm{~b}(\mathrm{PE})$ was conducted at $4^{\circ} \mathrm{C}$ for $30 \mathrm{~min}$ followed by washing. The cells were fixed with $2 \%$ paraformaldehyde for $20 \mathrm{~min}$ and washed. Mounting media with DAPI (Calbiochem, San Diego, CA) was added, and coverslips were placed on slides. Samples were examined using a confocal microscope (Zeiss 510 Meta; Carl Zeiss Microimaging, Thornwood, $\mathrm{NY}$ ) and analyzed with Imaris software.

Statistics. Data were analyzed by Student's $t$-test or analysis of variance using the statistical software program SigmaStat (Chicago, IL). Analysis of variance was used for comparison of more than two groups. A $P$ value of 0.05 or less was considered statistically significant. Data are representative of experiments repeated two to three times.

SUPPLEMENTARY MATERIAL is linked to the online version of the paper at http://www.nature.com/mi

\section{ACKNOWLEDGMENTS}

This study was funded by National Institutes of Health grant PO1 AI057986; NIH/NIGMS MBRS-RISE GM60655. We thank Melissa Contreras from UTSA for technical expertise. We also thank Colleen Witt (RCMI Imaging Center) for confocal microscopy assistance.

\section{DISCLOSURE}

The authors declared no conflict of interest.

(C) 2011 Society for Mucosal Immunology

\section{REFERENCES}

1. Dennis, D.T. et al. Tularemia as a biological weapon: medical and public health management. JAMA 285, 2763-2773 (2001).

2. Ellis, J., Oyston, P.C., Green, M. \& Titball, R.W. Tularemia. Clin. Microbiol. Rev. 15, 631-646 (2002).

3. Saslaw, S., Eigelsbach, H.T., Prior, J.A., Wilson, H.E. \& Carhart, S. Tularemia vaccine study. II. Respiratory challenge. Arch. Intern. Med. 107, 702-714 (1961).

4. Lai, X.H., Golovliov, I. \& Sjostedt, A. Expression of IglC is necessary for intracellular growth and induction of apoptosis in murine macrophages by Francisella tularensis. Microb. Pathog. 37, 225-230 (2004). 
5. Balagopal, A. et al. Characterization of the receptor-ligand pathways important for entry and survival of Francisella tularensis in human macrophages. Infect. Immun. 74, 5114-5125 (2006).

6. Anthony, L.D., Burke, R.D. \& Nano, F.E. Growth of Francisella spp. in rodent macrophages. Infect. Immun. 59, 3291-3296 (1991).

7. Bonquist, L., Lindgren, H., Golovliov, I., Guina, T. \& Sjostedt, A. MgIA and Igl proteins contribute to the modulation of Francisella tularensis live vaccine strain-containing phagosomes in murine macrophages. Infect. Immun. 76, 3502-3510 (2008).

8. Ketavarapu, J.M. et al. Mast cells inhibit intramacrophage Francisella tularensis replication via contact and secreted products including IL-4. Proc. Natl Acad. Sci. USA 105, 9313-9318 (2008).

9. Ierna, M.X., Scales, H.E., Saunders, K.L. \& Lawrence, C.E. Mast cell production of IL-4 and TNF may be required for protective and pathological responses in gastrointestinal helminth infection. Mucosal Immunol. 1, 147-155 (2008).

10. Galli, S.J. et al. Mast cells as "tunable" effector and immunoregulatory cells: recent advances. Annu. Rev. Immunol. 23, 749-786 (2005).

11. Malaviya, R., Ikeda, T., Ross, E. \& Abraham, S.N. Mast cell modulation of neutrophil influx and bacterial clearance at sites of infection through TNF-alpha. Nature 381, 77-80 (1996).

12. Masuda, A. et al. Interleukin-15 induces rapid tyrosine phosphorylation of STAT6 and the expression of interleukin-4 in mouse mast cells. 59. J. Biol. Chem. 275, 29331-29337 (2000).

13. Malaviya, R. \& Georges, A. Regulation of mast cell-mediated innate immunity during early response to bacterial infection. Clin. Rev. Allergy Immunol. 22, 189-204 (2002).

14. Malaviya, R. et al. Mast cell phagocytosis of FimH-expressing enterobacteria. J. Immunol. 152, 1907-1914 (1994).

15. Sher, A., Hein, A., Moser, G. \& Caulfield, J.P. Complement receptors promote the phagocytosis of bacteria by rat peritoneal mast cells. Lab. Invest. 41, 490-499 (1979).

16. Nakae, S. et al. Mast cells enhance T cell activation: importance of mast cell costimulatory molecules and secreted TNF. J. Immunol. 176, 2238-2248 (2006).

17. Burke, S.M. et al. Human mast cell activation with virus associated stimuli leads to the selective chemotaxis of natural killer cells by a CXCL8 dependent mechanism. Blood 111, 5467-5476 (2008).

18. Moon, T.C. et al. Advances in mast cell biology: new understanding of heterogeneity and function. Mucosal Immunol. 3, 111-128 (2010).

19. Levi-Schaffer, F., Temkin, V., Malamud, V., Feld, S. \& Zilberman, Y. Mast cells enhance eosinophil survival in vitro: role of TNF-alpha and granulocyte-macrophage colony-stimulating factor. J. Immunol. 160, 5554-5562 (1998).

20. Lemaire, C., Andrau, K., Fraisse, C.S., Adam, A. \& Souvannavong, V. IL-4 inhibits apoptosis and prevents mitochondrial damage without inducing the switch to necrosis observed with caspase inhibitors. Cell Death Differ. 6, 813-820 (1999).

21. Lai, X.H. \& Sjostedt, A. Delineation of the molecular mechanisms of Francisella tularensis-induced apoptosis in murine macrophages. Infect. Immun. 71, 4642-4646 (2003).

22. Vermes, I., Haanen, C., Steffens-Nakken, H. \& Reutelingsperger, C. A novel assay for apoptosis. Flow cytometric detection of phosphatidylserine expression on early apoptotic cells using fluorescein labelled Annexin V. J. Immunol. Methods 184, 39-51 (1995).

23. Alam, A. et al. Specific activation of the cysteine protease CPP32 during the negative selection of T cells in the thymus. J. Exp. Med. 186, 1503-1512 (1997)

24. Pastorino, J.G., Chen, S.T., Tafani, M., Snyder, J.W. \& Farber, J.L. The overexpression of Bax produces cell death upon induction of the mitochondrial permeability transition. J. Biol. Chem. 273, 7770-7775 (1998).

25. Kaplan, M.H., Schindler, U., Smiley, S.T. \& Grusby, M.J. Stat6 is required for mediating responses to IL-4 and for development of Th2 cells. Immunity 4, 313-319 (1996)

26. Anjum, R., Joshi, P. \& Khar, A. Induction of apoptosis in AK-5 tumor cells by a serum factor from tumor rejecting animals: cytochrome $c$ release independent of Bcl-2 and caspases. Cell Death Differ. 8, 1038-1046 (2001).
27. Porcheray, F. et al. Macrophage activation switching: an asset for the resolution of inflammation. Clin. Exp. Immunol. 142, 481-489 (2005).

28. Wickstrum, J.R. et al. Francisella tularensis induces extensive caspase-3 activation and apoptotic cell death in the tissues of infected mice. Infect. Immun. 77, 4827-4836 (2009).

29. Henry, T., Brotcke, A., Weiss, D.S., Thompson, L.J. \& Monack, D.M. Type I interferon signaling is required for activation of the inflammasome during Francisella infection. J. Exp. Med. 204, 987-994 (2007).

30. Dufort, F.J. et al. Cutting edge: IL-4-mediated protection of primary B lymphocytes from apoptosis via Stat6-dependent regulation of glycolytic metabolism. J. Immunol. 179, 4953-4957 (2007).

31. Fairbairn, I.P., Stober, C.B., Kumararatne, D.S. \& Lammas, D.A. ATPmediated killing of intracellular mycobacteria by macrophages is a P2X(7)dependent process inducing bacterial death by phagosome-lysosome fusion 1. J. Immunol. 167, 3300-3307 (2001).

32. Kusner, D.J. \& Barton, J.A. ATP stimulates human macrophages to kill intracellular virulent Mycobacterium tuberculosis via calcium-dependent phagosome-lysosome fusion. J. Immunol. 167, 3308-3315 (2001).

33. Schulert, G.S. \& Allen, L.A. Differential infection of mononuclear phagocytes by Francisella tularensis: role of the macrophage mannose receptor. J. Leuk. Biol. 80, 563-571 (2006).

34. Griffiths, G., Hoflack, B., Simons, K., Mellman, I. \& Kornfeld, S. The mannose 6-phosphate receptor and the biogenesis of lysosomes. Cell 52, 329-341 (1988).

35. Lee, S.J. et al. Mannose receptor-mediated regulation of serum glycoprotein homeostasis. Science 295, 1898-1901 (2002).

36. Ben Nasr, A. et al. Critical role for serum opsonins and complement receptors CR3 (CD11b/CD18) and CR4 (CD11c/CD18) in phagocytosis of Francisella tularensis by human dendritic cells (DC): uptake of Francisella leads to activation of immature DC and intracellular survival of the bacteria. J. Leukoc. Biol. 80, 774-786 (2006).

37. Abraham, S.N., Thankavel, K. \& Malaviya, R. Mast cells as modulators of host defense in the lung. Front. Biosci. 2, d78-87 (1997).

38. Marshall, J.S. Mast-cell responses to pathogens. Nat. Rev. Immunol. 4, 787-799 (2004).

39. Degterev, A. \& Yuan, J. Expansion and evolution of cell death programmes. Nat. Rev. Mol. Cell Biol. 9, 378-390 (2008).

40. Wurster, A.L., Rodgers, V.L., White, M.F., Rothstein, T.L. \& Grusby, M.J. Interleukin-4-mediated protection of primary B cells from apoptosis through Stat6-dependent up-regulation of Bcl-xL. J. Biol. Chem. 277, 27169-27175 (2002).

41. Sharma, P. et al. Redox regulation of interleukin-4 signaling. Immunity 29 , 551-564 (2008).

42. Stein, M., Keshav, S., Harris, N. \& Gordon, S. Interleukin 4 potently enhances murine macrophage mannose receptor activity: a marker of alternative immunologic macrophage activation. J. Exp. Med. 176, 287-292 (1992).

43. Beharka, A.A. et al. Pulmonary surfactant protein A up-regulates activity of the mannose receptor, a pattern recognition receptor expressed on human macrophages. J. Immunol. 169, 3565-3573 (2002).

44. Kudo, K. et al. Pulmonary collectins enhance phagocytosis of Mycobacterium avium through increased activity of mannose receptor. J. Immunol. 172, 7592-7602 (2004).

45. Shirey, K.A., Cole, L.E., Keegan, A.D. \& Vogel, S.N. Francisella tularensis live vaccine strain induces macrophage alternative activation as a survival mechanism. J. Immunol. 181, 4159-4167 (2008).

46. Idkowiak-Baldys, J., Baldys, A., Raymond, J.R. \& Hannun, Y.A. Sustained receptor stimulation leads to sequestration of recycling endosomes in a classical protein kinase C- and phospholipase D-dependent manner. J. Biol. Chem. 284, 22322-22331 (2009).

47. Noben-Trauth, N. et al. An interleukin 4 (IL-4)-independent pathway for CD4+ T cell IL-4 production is revealed in IL-4 receptor-deficient mice. Proc. Natl Acad. Sci. USA 94, 10838-10843 (1997).

48. Arulanandam, B.P., Lynch, J.M., Briles, D.E., Hollingshead, S. \& Metzger, D.W. Intranasal vaccination with pneumococcal surface protein $A$ and interleukin-12 augments antibody-mediated opsonization and protective immunity against Streptococcus pneumoniae infection. Infect. Immun. 69, 6718-6724 (2001). 